\title{
Practices of Dentists about Digital Techniques in Dental Radiology and Radiographic Safety
}

\author{
Arshad Hasan ${ }^{1}$ \\ Javeria Ali Khan ${ }^{2}$ \\ Batool Ali ${ }^{3}$ \\ Zareen Afshan ${ }^{4}$ \\ Mirza Nidal Shakir ${ }^{5}$ \\ Syad Yawar Ali Shah ${ }^{6}$ \\ BDS, FCPS \\ BDS, FCPS \\ BDS, FCPS \\ BDS, MDS \\ BDS \\ BDS
}

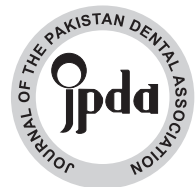

OBJECTIVE: Digital radiography has many advantages over conventional radiography. However, the adaptation of this new technique is still slow. Moreover, safety measures related to radiography remain an important but neglected area of dental practice. The objective of this study was to assess practices of dentists about digital imaging techniques in dental radiology and radiographic safety.

METHODOLOGY: A questionnaire based study was conducted among dental practitioners of Karachi. Convenience sampling technique was used to draw the sample of 164 general practitioners from Karachi. A 4 part questionnaire was used. Part 1 recorded basic demographic data, while part 2,3 and 4 focused on specific aspects of digital radiography and safety. SPSS version 21 was used for statistical analysis. Descriptive statistics was used to calculate frequency and percentage of responses. Chi square test was used to asses associations at a significance level of 0.05 .

RESULTS: A total of 164 fully filled forms were included in final analysis. Majority of respondents $(\mathrm{n}=113,69 \%)$ were users of digital radiography. The main reason $(n=36,70.7 \%)$ for not using it was cost of equipment. Main reason for prescribing a CBCT was for implants $(n=55,33.5 \%)$. Most respondents $(n=99,60.4 \%)$ used lead protection for radiographing pregnant patients. A total of 64 respondents $(39 \%)$ themselves held xray films in patient's mouth. There was significant association $(\mathrm{p}=0.002)$ between female gender and not performing radiographs $(\mathrm{p}=0.005)$.

CONCLUSIONS: Although the adaptation of digital techniques was satisfactory, the radiation safety practices of dental surgeons were inadequate.

KEY WORDS: Digital Dental Radiography, Cone Beam Computed Tomography, Radiation Safety.

HOW TO CITE: Hasan A, Khan JA, Ali B, Afshan Z, Shakir MN, Shah SYA. Practices of dentists about digital techniques in dental radiology and radiographic safety. J Pak Dent Assoc 2019;28(4):181-186.

DOI: https://doi.org/10.25301/JPDA.284.181

Received: 05 August 2019, Accepted: 19 August 2019

\section{INTRODUCTION}

$\mathrm{R}$ adiology is one of the most important tool for a dental practitioner to perform routine procedures. From diagnosis to treatment and follow-up, radiography plays an integral role in ensuring a successful outcome. ${ }^{1}$ Digital radiology was introduced to dentistry in 90 's. ${ }^{2}$ Lately, there has been a steady growth of digital technology worldwide. Digital sensors of various types have

1. Professor, Department of Operative Dentistry, Dow Dental College DUHS, Karachi

2. Assistant Professor, Department of Operative Dentistry, Dow Dental College DUHS, Karachi.

3. Assistant Professor, Department of Orthodontics, Dow Dental College DUHS, Karachi.

4. Lecturer, Department of Operative Dentistry, Dow Dental College DUHS, Karachi.

5. Lecturer, Department of Operative Dentistry, Dow Dental College DUHS, Karachi.

6. Lecturer, Department of Orthodontics, Dow Dental College DUHS, Karachi.

Corresponding author: "Prof. Dr. Arshad Hasan" < arshad.hasan@duhs.edu.pk > become a part of mainstream dentistry. ${ }^{3}$

Along-with the two dimensional digital imaging, a lot of research and advancement in three dimensional dental imaging has also taken place. 'Cone Beam Computed Tomography' or simply CBCT has also become a standard of care for diagnosis and treatment planning worldwide. The advancement has reached such a stage where information from a CBCT scan is merged digitally with an intra oral scan to produce virtual anatomical designs of patients oral structures. This combined with a $3 \mathrm{D}$ printer enables the dental practitioner to deliver treatments with pin point accuracy and minimum morbidity. ${ }^{4}$

In spite of all these advancements, and reduction of radiation dosage due to digital techniques, basic rules of safety still apply. There has been a concern among researchers 
that digital techniques might introduce a false sense of security regarding the safety measures. There have been some reports of more retakes of un-acceptable radiographs due to ease of using digital radiography, thus increasing the radiation dose. $^{3}$

Various researchers worldwide have reported on comparisons between digital and conventional radiography usage among dental practitioners. A study from Lithuania reported that younger dentists are more likely to use radiographs for routine diagnosis. A film holder was not often used. ${ }^{5}$ Another study reported that the digital technology was user friendly but high cost was main factor for nonusage of digital radiography. ${ }^{6}$ While a study from Norway revealed that the dentists belonging to private practices and working in group practice are more likely to adopt this technology. ${ }^{7}$ Perhaps most striking results were from Sweden where a recent survey revealed that $98 \%$ Dentists have shifted to digital radiography. ${ }^{3}$

Reported research on CBCT reveals that although dentists are aware of it, they lack skill to interpret a scan. Also a need to include CBCT in undergraduate curriculum was expressed in surveys. ${ }^{8}{ }^{8}$ A Turkish study revealed increasing knowledge amongst dentists about the CBCT and radiation safety. ${ }^{10}$ An Indian study on the other hand reported poor safety practices of dentist in dental radiology. ${ }^{11}$

There is a lack of local data on the subject. Studies have compared conventional and digital radiographs for their accuracy during diagnosis or treatment. ${ }^{12,13}$ The only local survey from Islamabad revealed that a mere $61 \%$ had heard about CBCT. ${ }^{14}$ We could not find survey from Karachi on either Digital Radiography, CBCT or radiation safety practices among dental surgeons. It was therefore, the objective of this questionnaire based survey to assess practices of dentists about digital imaging techniques in dental radiology and radiographic safety.

\section{METHODOLOGY}

This study was conducted among the private practitioners of Karachi from January to July 2019. An institutional ethical committee approval (IRB-1266/DUHS/19) was taken before commencing the study.

A modified form of questionnaire (Annex1) previously reported in the literature was used. ${ }^{7,10,15}$ It was based on multiple choices and respondents were asked to choose either one or more options based on type of question. Briefly, it consisted of four parts. Part one collected all basic demographic data, part two collected information about digital radiology, part three was about $\mathrm{CBCT}$ and part four collected data about radiation safety practices of the dental surgeons. The questionnaire was validated and pre-tested before using in the study. The process of validation included filling of form by 10 percent of total sample size. Based on the results gathered from the validation process, fine tuning of the questionnaire was done prior to commencing the study. The sample collected during validation was not made a part of final analysis.

Convenience sampling technique was used to draw the sample. We included dental surgeons working in clinical settings either in private clinics or in academic institutes, while those working in basic sciences or pure research settings with no clinical contact with patients were excluded. Also incompletely filled forms were excluded. A total of 250 questionnaires were sent to various dental clinics of Karachi. A total of 177 forms (response rate 70\%) were received. Out of these, 164 were completely filled. Thus, 164 participants were included in the study as calculated in the sample size calculation described below.

\section{SAMPLE SIZE CALCULATION}

Sample size was calculated using Openepi online calculator. A $82 \%$ usage of digital radiography in a Dutch survey was used at $95 \%$ confidence level and $80 \%$ power. ${ }^{6}$ A sample size of 159 was calculated.

\section{STATISTICAL ANALYSIS}

The data was analyzed using SPSS version 21 for Windows. Descriptive statistics was used to calculate frequencies and percentages of responses. Chi square test was used to asses associations at a significance level of $\leq 0.05$.

\section{RESULTS}

Basic demographic information of study participants is presented in Table no 1. Table 2 presents responses to

Table 1: Basic demographic information

\begin{tabular}{|l|l|l|l|}
\hline & & $\mathbf{n}$ & $\%$ \\
\hline Age & $25-40$ & 161 & 98 \\
& $>40$ & 3 & 2 \\
\hline \multirow{2}{*}{ Gender } & Male & 71 & 43 \\
& Female & 93 & 57 \\
\hline Status & PG & 69 & 42 \\
& GP & 57 & 34 \\
& Academician & 38 & 24 \\
\hline \multirow{2}{*}{ Experience } & $<5$ years & 74 & 45 \\
& $5-10$ years & 66 & 40 \\
& $>10$ years & 24 & 15 \\
& & & \\
\hline
\end{tabular}

$\mathrm{PG}=$ post graduate residents

$\mathrm{GP}=$ general practitioners 
Hasan A/ Khan JA/ Ali B/

Table 2: Responses of study population to questions related to Radiography Practices

\begin{tabular}{|c|c|c|}
\hline & & \begin{tabular}{l|l} 
n & (\%)
\end{tabular} \\
\hline Digital imaging user & $\begin{array}{l}\text { Yes } \\
\text { No }\end{array}$ & $\begin{array}{l}113(69) \\
51(31)\end{array}$ \\
\hline Reasons for Using & $\begin{array}{l}\text { Less radiation dose } \\
\text { Efficient dental practice } \\
\text { No chemical processing } \\
\text { Less pollution } \\
\text { Easy record keeping } \\
\text { Ability to adjust and measure radiograpt } \\
\text { No artifacts } \\
\text { Patient Satisfaction } \\
\text { All of above } \\
\text { Total }\end{array}$ & $\begin{array}{l}10(8.8) \\
43(38) \\
12(10.6) \\
3(2.7) \\
6(5.3) \\
5(4.7) \\
4(3.5) \\
1(0.8) \\
29(25.6) \\
113(100)\end{array}$ \\
\hline $\begin{array}{l}\text { Reasons for not } \\
\text { Using }\end{array}$ & $\begin{array}{l}\text { Expensive } \\
\text { Not have equipment } \\
\text { Lack of comfort with technology } \\
\text { Lack of technical staff } \\
\text { Patient Comfort } \\
\text { Difficulty in record keeping } \\
\text { Unsatisfactory Image Quality } \\
\text { Total }\end{array}$ & $\begin{array}{l}36(70.7) \\
4(7.8) \\
3(5.8) \\
4(7.8) \\
2(3.9) \\
1(2) \\
1(2) \\
51(100)\end{array}$ \\
\hline $\begin{array}{l}\text { Exposure time of } \\
\text { Digital and } \\
\text { conventional same }\end{array}$ & $\begin{array}{l}\text { Yes } \\
\text { No } \\
\text { I don't know }\end{array}$ & $\begin{array}{l}55(33.5) \\
8250) \\
27(16.5)\end{array}$ \\
\hline $\begin{array}{l}\text { Digital Imaging for } \\
\text { which radiograph }\end{array}$ & $\begin{array}{l}\text { Panoramic } \\
\text { Intra-Oral } \\
\text { Cephalometric } \\
\text { CBCT } \\
\text { All } \\
\end{array}$ & $\begin{array}{l}17(10.3) \\
88(53.7) \\
1(0.6) \\
1(0.6) \\
57(34.8)\end{array}$ \\
\hline Age of equipment & $\begin{array}{l}1-5 \text { years } \\
6-10 \\
>10\end{array}$ & $\begin{array}{l}117(77) \\
34(15.1) \\
13(7.9)\end{array}$ \\
\hline Kind of Sensor & $\begin{array}{l}\text { Hard sensor } \\
\text { Flexible Phosphor plate }\end{array}$ & $\begin{array}{l}82(66) \\
42(34)\end{array}$ \\
\hline $\begin{array}{l}\text { Since how many } \\
\text { years using digital }\end{array}$ & $\begin{array}{l}1-5 \text { years } \\
5-10 \\
>10\end{array}$ & $\begin{array}{l}86(76.2) \\
2320.3) \\
4(3.5)\end{array}$ \\
\hline $\begin{array}{l}\text { How many } \\
\text { radiographs per day }\end{array}$ & $\begin{array}{l}<10 \\
10-20 \\
21-30 \\
>30\end{array}$ & $\begin{array}{l}135(82.4) \\
25(15.2) \\
1(0.6) \\
3(1.8)\end{array}$ \\
\hline $\begin{array}{l}\text { Perform } \\
\text { Radiographs } \\
\text { yourself }\end{array}$ & $\begin{array}{l}\text { Yes } \\
\text { Not perform due to lack of equipment } \\
\text { Not perform due to lack of knowledge } \\
\text { Not perform at all }\end{array}$ & $\begin{array}{l}97(60) \\
16(10) \\
8(5) \\
43(25)\end{array}$ \\
\hline
\end{tabular}

$\mathrm{CBCT}=$ Cone beam computed tomography

Table 3: Responses to CBCT related questions

\begin{tabular}{|l|l|l|}
\hline Ever Advised CBCT & Yes & $101(62.3)$ \\
& No & $63(37.7)$ \\
\hline $\begin{array}{l}\text { In which situation prefer } \\
\text { CBCT }\end{array}$ & Trauma & $8(4.8)$ \\
& Cyst/ tumor & $20(12.4)$ \\
& Implant & $55(33.5)$ \\
& Dental Caries & $1(0.6)$ \\
& Periodontal Disease & $0(0)$ \\
& Endodontics & $4(2.6)$ \\
& Impaction & $2917.7)$ \\
& Trauma/ Implant/ Impaction & $28(17)$ \\
& More than 3 options & $19(11.4)$ \\
\hline Advantages of CBCT & Low radiation compared to medical CT & $62(37.8)$ \\
& Short scanning time & $14(8.5)$ \\
& Image processing easier due to limited & $27916.5)$ \\
& beam & $4929.8)$ \\
& Reconstruction possible on PC & $6(3.7)$ \\
& 2 option or more & $6(3.7)$ \\
\hline
\end{tabular}

$\mathrm{CBCT}=$ Cone beam computed tomography
Table 4: Responses of study population to questions related to Radiation Safety

\begin{tabular}{|l|l|l|}
\hline Policy about & Avoid at all costs & $39(24)$ \\
pregnant patients & Use lead shield & $99(60.4)$ \\
& Perform without protection & $3(1.8)$ \\
& Take precautions only in $1^{\text {st }}$ and $3^{\text {rd }}$ trimester & $15(9.1)$ \\
& 2 or more options & $8(4.7)$ \\
\hline How do you hold & With film holder & $69(42)$ \\
Sensor in mouth & Patient holds the film & $31(19)$ \\
& Operator holds the film & $64(39)$ \\
\hline Walls of room & Yes & $47(29)$ \\
covered with lead & No & $117(71)$ \\
\hline Use Lead apron/ & Yes & $105(64)$ \\
thyroid Collar & No & $59(36)$ \\
\hline Where do you & Behind protective wall & $55(33.5)$ \\
stand & Behind lead screen & $24(14.6)$ \\
& Near patient without wearing lead apron & $53(32.4)$ \\
& Near patient wearing lead apron & $32(19.5)$ \\
\hline Collimator type & Short cone Round & $66(50)$ \\
& Long cone Round & $43(32.6)$ \\
& Pointed cone round & $9(6.8)$ \\
& Short cone Rectangular & $8(6.1)$ \\
& Long cone Rectangular & $4(3)$ \\
& Pointed cone Rectangular & $2(1.5)$ \\
\hline
\end{tabular}

Table 5: Association between study variables

\begin{tabular}{|l|l|l|l|l|}
\hline & Age & Gender & $\begin{array}{l}\text { Professional } \\
\text { Status }\end{array}$ & $\begin{array}{l}\text { Professional } \\
\text { Experience }\end{array}$ \\
\hline $\begin{array}{l}\text { Digital Xray } \\
\text { user }\end{array}$ & 0.337 & 0.323 & 0.356 & 0.494 \\
\hline Sensor type & 0.735 & 0.29 & 0.39 & 0.687 \\
\hline $\begin{array}{l}\text { Reasons for } \\
\text { NOT using } \\
\text { Digital } \\
\text { radiographs }\end{array}$ & 0.246 & 0.529 & 0.191 & $0.019 *$ \\
\hline $\begin{array}{l}\text { Reasons for } \\
\text { Using Digital } \\
\text { Radiographs }\end{array}$ & 0.957 & 0.388 & 0.75 & $0.005 *$ \\
\hline $\begin{array}{l}\text { Perform } \\
\text { Radiographs } \\
\text { yourself }\end{array}$ & 0.902 & $0.002 *$ & 0.317 & 0.544 \\
\hline $\begin{array}{l}\text { Hold xray in } \\
\text { mouth }\end{array}$ & 0.55 & 0.596 & 0.56 & 0.085 \\
\hline $\begin{array}{l}\text { Radiograph } \\
\text { for pregnant } \\
\text { patient }\end{array}$ & 0.592 & 0.741 & 0.665 & 0.143 \\
\hline
\end{tabular}

\section{* is significant}

questions about radiography practices. Majority of respondents $(n=113,69 \%)$ were users of digital radiography. The main reason $(n=36,70.7 \%)$ for not using it among the non -users was cost of equipment. Majority users $(n=86$, $76.2 \%$ ) started using digital radiography within last 5 years. Table 3 represents responses about CBCT usage. Majority 
$(n=101,62.3 \%)$ had prescribed it and main reason for using it was dental implants $(n=55,33.5 \%)$. The responses about radiation safety practices is presented in table 4 . Most respondents $(n=99,60.4 \%)$ used lead protection for radiographing pregnant patients. A total of 64 respondents (39\%) themselves held xray films in patient's mouth. Responding to the question if there is adequate teaching of radiology in undergrad course, most $(n=119,72.6 \%)$ responded in negative. While most $(n=74,45.4 \%)$ of the respondents had never attended a seminar on dental radiology. The associations between various study variables is presented in table 5. There was significant association $(p=0.002)$ between female gender and not performing radiographs at all. Similarly, significant associations were found between professional experience and reasons for using or not using digital radiographs $(\mathrm{p}=0.005$ and $\mathrm{p}=0.019)$.

\section{DISCUSSION}

Present study was a first of its kind from the region since it combined three aspects of contemporary dental radiology; Digital Radiography, CBCT and radiation safety practices among dental surgeons. Briefly our results suggest an encouraging situation as far as the usage of digital radiography is concerned. The usage was found to be $69 \%$ among study participants. Hard sensor was the most common type of intraoral digital sensor $(n=82,66 \%)$. Usage of CBCT was $62 \%$. Radiation safety practices were as follows. Sixty percent used lead aprons for pregnant patients. While, 39\% held $\mathrm{x}$-ray films in patient's mouth. Majority $(\mathrm{n}=105,64 \%)$ used lead aprons.

Digital radiography has only recently become popular in the region after influx of cost effective products. However, as our results suggest the cost is still prohibitive for the most. The global use of digital radiography varies from region to region. Usage of digital radiography was reported to be $98 \%$ among Swedish dentists. ${ }^{3}$ Two Dutch studies reported a usage of $82 \%$ and $90 \%$ among dental paractiioners. ${ }^{6,16} \mathrm{~A}$ study from New-Zealand reported a usage of $80 \%$ among its respondents. ${ }^{17}$ A Belgian study reported a $94 \%$ usage. ${ }^{18}$ All of these figures of usage are more than reported in the present study. The difference of usage is clearly related to the socioeconomic background of these technologically advanced countries where digital radiography was introduced more than two decades ago. ${ }^{2}$ Regionally the use of digital radiography was reported at $15-54 \%$ in a study from Maharashtra India. ${ }^{19}$ Although this it is less than our results, one of the limitation of present study is its sampling technique which may not truly represent the population. Hence, the actual usage may be less and closer to that reported by Indian study. Another study from Bangalore reported $83 \%$ usage. ${ }^{15}$
This result is closer to ours.

The most common reason for not adopting digital radiography in the present study was its high cost. Results of other studies also support our findings. , $7,20,21^{2}$ Similarly, the most common reason for using Digital Radiography was its efficiency in dental practice. Norwegian study reported lack of chemicals as most common reason, where as Brain et al reported time efficiency as most common reason. ${ }^{7,20}$ Similarly, ease in working was reported by Svenson et al. ${ }^{3}$ All of these results agree with present study. Improved communication was most common reason for a study from New Zealand. ${ }^{17}$ The reason for disagreement of this study could be a different questionnaire used in that study.

The most common type of sensor used by respondents of present study was hard type. Other studies also reported the more frequent use of hard sensor. ${ }^{3,6,20}$ In present study the younger age group was more likely to adopt digital technology. This results contrasts with that of Wenzel where that found more users of digital radiography in 56-65 age group. We didn't have any respondent in that age category. The reason for this dis-agreement can be due to differences in basic demographics of practicing dentists between the two regions.

Cone beam computed tomography (CBCT) was only recently introduced in Pakistan. Sixty two percent respondents reported prescribing $\mathrm{CBCT}$ which is an encouraging figure. A study from India reported $82 \%$ prescription of CBCT. ${ }^{15}$ In contrast, a Turkish study reported that $30 \%$ of respondents ever prescribed CBCT. ${ }^{10}$ The difference in results may be due to regional variations and lack of access to CBCT or its lack of knowledge. Most common indication for prescribing CBCT in the present study was Implantology. This fact was corroborated by other studies. ${ }^{9,10,15,22}$

Radiation safety is an important aspect of contemporary radiology. Our results suggests a need for improvement in certain aspects. Sixty percent respondents reported using lead aprons for pregnant patients while $24 \%$ avoided taking radiographs. The American Dental Association's policy of radiographs for pregnant patients states that a radiograph can be taken after using a lead shield covering thyroid and abdomen. ${ }^{23}$ It is therefore recommended that continuing dental education programs may be conducted to improve the prescription practices. A study from India reported similar results to ours, $31 \%$ dentists avoided taking radiographs during pregnancy. ${ }^{11}$ Perhaps most surprising finding was about holding the film in patient's mouth. Thirty nine percent respondents declared that they held xray film in patient's mouth. Similar results were reported by studies from India, Turkey and Lithuania. ${ }^{5,11,24,25}$ Similarly, 64\% reported using a lead apron. A study from Turkey reported a 50\% usage which is closer to our results. ${ }^{24}$ In contrast Soheyl et al 
reported only $19 \%$ dentists used lead apron in their study. ${ }^{25}$

According to principals of ALARA for dentistry, short cone and rectangular collimator is recommended. ${ }^{26} \mathrm{Almost}$ half respondents of our study reported using a short cone and round collimator. In contrast Soheyl et al reported a 50 usage of long cone but a very low usage of rectangular collimator. ${ }^{25}$ IIguy et al also reported contrasting results. Almost half respondents used long cone and very few used rectangular collimators. ${ }^{24}$ The variation in results represents a regional preference in use of devices but also shows a lack of training for dentists in adopting safe practices.

Another surprising finding was the significant association of gender with performing radiographs. Significantly more females avoided performing radiographs themselves. It is apparent from the discussion that there are a lot of poor practices among the dental surgeons. The radiation safety practices are inadequate. With increasing ease of taking a digital radiograph, the number of radiographs will also increase and thus combined with poor radiation safety, a grave situation may emerge for the practitioner and patient alike. It is therefore, recommendation of the authors that continuing dental education programs targeting the practicing dentists may be initiated to improve their radiation safety practices. It is also recommended to add dental radiology as a separate subject in undergraduate course and as a separate mandatory department in dental colleges. These departments must be equipped with quality equipment and certified from nuclear radiation agency. Also the staff should be qualified in this specialty. In contrast to the we established medical radiology, dental radiology is still in infancy in Pakistan. Efforts are needed from regulatory authority and dental college administrations to take note of this appalling situation. We also report a small sample size and lack of representation of all regions of city as our limitations.

\section{CONCLUSION}

The usage of digital radiography was high. Cost was the main reason for non-usage. CBCT was prescribed mainly for implants. The radiation safety measures were generally poor.

\section{CONFLICT OF INTEREST}

None declared

\section{REFERENCES}

1. Whaites E, Drage N. Essentials of dental radiography and radiology, Edinburgh [etc.]: Churchill Livingstone Elsevier;2015.

2. Tasleem H, Arshad H. Digital Radiography in Dentistry. J Pak Dent Assoc. 2004;13:91-8.
3. Svenson B, Ståhlnacke K, Karlsson R, Fält A. Dentists' use of digital radiographic techniques: Part I - intraoral X-ray: a questionnaire study of Swedish dentists. Acta Odontol Scand. 2018;76:111-18. https://doi.org/10.1080/00016357.2017.1387930

4. Lin WS, Harris BT, Morton D. Use of CBCT Imaging, Open-Source Modeling Software, and Desktop Stereolithography 3D Printing to Duplicate a Removable Dental Prosthesis-A Proof of Concept. Compend Contin Educ Dent. 2017;38:e5-e8.

5. Peciuliene V, Rimkuviene J, Maneliene R, Drukteinis S. Use of dental radiography among Lithuanian general dentists. Stomatol. 2009; 11:77-82.

6. Berkhout WER, Sanderink GCH, Van der Stelt PF. A comparison of digital and film radiography in Dutch dental practices assessed by questionnaire. Dentomaxillofac Radiol. 2002;31:93-9.

https://doi.org/10.1038/sj.dmfr.4600669

7. Wenzel A, Møystad A. Decision criteria and characteristics of Norwegian general dental practitioners selecting digital radiography. Dentomaxillofac Radiol. 2001;30:197-202.

https://doi.org/10.1038/sj.dmfr.4600612

8. Eltayeb AS, Satti A, Ahmad AG. Knowledge and Attitudes of Dentists towards Cone Beam Computed Tomography in Khartoum, Sudan. IOSR J Res Method Edu. 2017;7:32-5.

9. Hol C, Hellen-Halme K, Torgersen G, Nilsson M, Møystad A. How do dentists use CBCT in dental clinics? A Norwegian nationwide survey. Acta Odontol Scand. 2015;73:195-201.

https://doi.org/10.3109/00016357.2014.979866

10. Dölekoglu S, Fisekçioglu E, Ilgüy M, Ilgüy D. The usage of digital radiography and cone beam computed tomography among Turkish dentists. Dentomaxillofac Radiol. 2011;40:379-84

https://doi.org/10.1259/dmfr/27837552

11. Kasat VO, Ladda R, Joshi S, Giri PA, Pandya M, Shaikh S. Knowledge and practice regarding safety standards of oral radiology among dental practitioners in western Maharashtra, India. Oral Radiol. 2017;33:1-7.

https://doi.org/10.1007/s11282-016-0234-z

12. Qazi HS, Maxood A, Abdullah S. Comparison of radiographic and electronic working length in anterior teeth. Pak Oral Dent J. 2006;27:314.

13. Razie L, Ghafooriyan M, Shakeri MT. Diagnostic efficacy of digital and conventional radiography in periapical bone lesions. Pak Oral Dent J. 2007;27:23-6.

14. Jalil T, Zaman H, andMubashir Sharif MS. Knowledge and attitude of dental professionals towards cone beam computed tomography--a study done at AFID. Pak Oral Dent J. 2016;36:553-57.

15. Shetty SR, Castelino RL, Babu SG, Laxmana AR, Roopashri K. Knowledge and attitude of dentists towards cone beam computed tomography in mangalore-a questionnaire survey. 


\section{Hasan A/ Khan JA/ Ali B/ Afshan Z/ Shakir MN/ Shah SYA}

Austin J Radiol. 2015;2:1016.

16. van der Zande MM, Gorter RC, Aartman IHA, Wismeijer D. Adoption and Use of Digital Technologies among General Dental Practitioners in the Netherlands. PLOS ONE. 2015;10:e0120725. https://doi.org/10.1371/journal.pone.0120725

17. van der Zande MM. Digital technology use in dental practice 2017.

18. Snel R, Van De Maele E, Politis C, Jacobs R. Digital dental radiology in Belgium: a nationwide survey. Dentomaxillofacial Radiol. 2018;47:20180045.

https://doi.org/10.1259/dmfr.20180045

19. Galav A, Borah M, Sugandhi C, Rathod R, Satija N, Chauhan M. Attitude and practice of dental professionals towards using of advance radiographic technique: a cross-sectional descriptive study. J Res Dent. 2017;4:134-39.

https://doi.org/10.19177/jrd.v4e52016134-139

20. Brian J, Williamson G. Digital radiography in dentistry: a survey of Indiana dentists. Dentomaxillofacial Radiol. 2007;36:18-23. https://doi.org/10.1259/dmfr/18567861

21. Flores-Mir C, Palmer NG, Northcott HC, Khurshed F, Major PW.
Practices of dentists about digital techniques

Perceptions and attitudes of Canadian dentists toward digital and electronic technologies. J Can Dent Assoc. 2006;72:243.

22. Rai S, Misra D, Dhawan A, Tyagi K, Prabhat M, Khatri M. Knowledge, awareness, and aptitude of general dentists toward dental radiology and CBCT: A questionnaire study. J Ind Academy Oral Med Radiol. 2018;30:110-15.

23. Association AD. Oral Health Topics: X-Rays/Radiographs 2019 [Available from: https://www.ada.org/en/member-center/oral-healthtopics/x-rays.

24. Ilguy D, Ilguy M, Dincer S, Bayirli G. Survey of dental radiological practice in Turkey. Dentomaxillofac Radiol. 2005;34:222-27. https://doi.org/10.1259/dmfr/22885703

25. Sheikh S, Pallagatti S, Singla I, Gupta R, Aggarwal A, Singh R, et al. Survey of dental radiographical practice in states of Punjab and Haryana in India. J Investig Clin Dent. 2014;5:72-7. https://doi.org/10.1111/jicd.12016

26. Tugnait A, Clerehugh V, Hirschmann PN. Radiographic equipment and techniques used in general dental practice: a survey of general dental practitioners in England and Wales. J Dent. 2003;31:197-203. https://doi.org/10.1016/S0300-5712(03)00013-7 